\title{
Predicting multi-predator risk to elk (Cervus canadensis) using scats: Are migrant elk exposed to different predation risk?
}

\author{
Kara MacAulay $^{1}$, Eric Spilker ${ }^{1}$, Jodi Berg ${ }^{1}$, Mark Hebblewhite $^{2}$, and Evelyn Merrill ${ }^{1}$ \\ ${ }^{1}$ University of Alberta \\ ${ }^{2}$ University of Montana Missoula
}

May 17, 2021

\begin{abstract}
There is evidence that prey can perceive the risk of predation and alter their behaviour in response, resulting in changes in spatial distribution and potential fitness consequences. Previous approaches to mapping predation risk quantify predator space use to estimate potential predator-prey encounters, yet this approach does not account for successful predator attacks resulting in prey mortality. An exception is a prey kill-site, which reflects an encounter resulting in mortality, but obtaining these data can be expensive and requires time to accumulate adequate sample sizes. We illustrate an alternative approach using predator scat locations and their contents to quantify spatial predation risk for elk (Cervus canadensis) from multiple predators in Alberta, Canada. We combined predictions of scat-based resource selection functions for bears (Ursus arctos/U. americanus), cougars (Puma concolor), coyotes (Canis latrans), and wolves (C. lupus) based on scat-detection dog surveys with predictions for the probability that a predator-specific scat in a location contained elk. We evaluated our approach by comparing predictions to a predation risk model developed from elk kill sites and applied it to describing spatial patterns in predation risk that were consistent with changes in the distribution of elk over the past decade. We found a strong correlation between risk predicted by kill sites and risk predicted by our approach $(\mathrm{r}=0.98, \mathrm{P}<0.001)$. There was a spatial pattern to predation risk, where elk that migrated east of their winter range were exposed to highest risk from cougars, non-migratory elk were exposed to high risk from wolves and bears, and risk to elk that migrated west of their winter range into protected areas was high only from bears. The patterns in predator risk were consistent with changes in the migratory tactics in this population. The scat-based approach we present permits broad-scale inferences on predation risk for prey.
\end{abstract}

April 27, 2021

Kara M. MacAulay

CW405 - Biological Sciences Building

University of Alberta

Edmonton, Alberta, Canada T6G 2E9

kmacaula@ualberta.ca

RH: MacAulay et al. · Elk predation risk

Predicting multi-predator risk to elk (Cervus canadensis) using scats: Are migrant elk exposed to different predation risk?

KARA M. MacAULAY Department of Biological Sciences, University of Alberta, Edmonton, Alberta T6G 2E9, CANADAhttps://orcid.org/0000-0003-1001-6906 
ERIC G. SPILKER Department of Biological Sciences, University of Alberta, Edmonton, Alberta T6G 2E9, CANADA

JODI E. BERG Department of Biological Sciences, University of Alberta, Edmonton, Alberta T6G 2E9, CANADA https://orcid.org/ 0000-0003-0678-8137

MARK HEBBLEWHITE Wildlife Biology Program, Department of Ecosystem and Conservation Sciences, W. A. Franke College of Forestry and Conservation, University of Montana, Missoula, Montana 59812, USAhttps://orcid.org/0000-0001-5382-1361

EVELYN H. MERRILL Department of Biological Sciences, University of Alberta, Edmonton, Alberta T6G 2E9, CANADAhttps://orcid.org/0000-0001-7737-958X

1. ABSTRACT: There is growing evidence that prey can perceive the risk of predation and alter their behaviour in response, resulting in changes in spatial distribution and potential fitness consequences. Previous approaches to mapping predation risk across a landscape quantify predator space use to estimate potential predator-prey encounters, yet this approach does not account for successful predator attack resulting in prey mortality. An exception is a prey kill site, which reflects an encounter resulting in mortality, but obtaining these data can be expensive and requires time to accumulate adequate sample sizes.

2. We illustrate an alternative approach using predator scat locations and their contents to quantify spatial predation risk for elk(Cervus canadensis ) from multiple predators in Alberta, Canada. We combined spatial predictions of scat-based resource selection functions (RSFs) for bears (Ursus arctos/U. americanus), cougars (Puma concolor), coyotes (Canis latrans), and wolves (C. lupus) based on surveys with scat-detection dogs with predictions for the probability that a predator-specific scat in a location contained elk. We evaluated our approach by comparing predictions to a model of predation risk developed from elk kill sites and applied it to describing spatial patterns in predation risk that were consistent with changes in the distribution of elk over the past decade.

3. We found a strong correlation between risk predicted by kill sites and risk predicted by our approach $(r=0.98, P<0.001)$. There was a spatial pattern to predation risk, where elk that migrated east of their winter range were exposed to highest risk from cougars, non-migratory elk were exposed to high risk from wolves and bears, and risk to elk that migrated west of their winter range into protected areas was high only from bears. The patterns in predator risk were consistent with changes in the migratory tactics in this population.

4. The scat-based approach we present permits broad-scale inferences on predation risk for prey species that has advantages especially in multiple predator species.

\section{Key-words:}

- detection dog, elk, occurrence, partial migration, predation risk, resource selection functions, scat analysis, spatial ecology

\section{Introduction}

Large herbivores, like most prey species, make substantial investments in avoiding predation risk (Tolon et al., 2009). Risk of predation influences large herbivore habitat selection, grouping dynamics, and antipredator behaviours (Hebblewhite et al., 2006; Christianson \& Creel, 2010). As a result, large herbivore prey are often faced with making trade-offs in pursuing foraging opportunities while avoiding areas of high predation risk (Creel et al., 2005; Hebblewhite \& Merrill, 2009).

Lima \& Dill (1990) established a conceptual model of predation risk by identifying two fundamental components of Holling's (1959) disk equation for the risk of a prey being killed per unit time:

$P($ death $)=1-\exp (-\alpha d \mathrm{~T})$ eqn 1

where $\alpha$ is the probability of encounter and $d$ is the probability of death given an encounter during time (T). Their approach considers the two main stages of predation and highlights the conditional nature of mortality 
on attacks. However, it does not explicitly account for how predation risk may vary spatially.

Because spatial data for predator and prey are increasingly available, predation risk to prey has been related to a predator's abundance, occurrence, intensity of use or resource selection (Theuerkauf \& Rouys, 2008; Thaker et al., 2011; Moll et al., 2017). For example, White et al. (2009) related wolf (Canis lupus ) density as a metric of predation risk to changes in elk (Cervus canadensis) nutrition in Yellowstone National Park during and after wolf recolonization, whereas predation risk from wolves and bears was estimated for a range of prey using RSFs (Gustine et al., 2006). Hebblewhite \& Merrill (2007) combined these approaches by weighting RSFs of wolves by their spatial abundance to reflect the importance of the numeric response in predation risk. Although commonly used, these metrics ignore a key component of predation - the probability of death given an encounter (Lima \& Dill, 1990). Encounters, however, are extremely difficult to observe directly, even indirectly (e.g ., Eriksen et al., 2009; Whittington et al., 2011). As a result, studies have estimated risk of mortality solely using prey kill sites (Smith et al., 2005). For example, Kauffman et al. (2007) compared wolf kill sites to random locations in Yellowstone National Park to identify landscape features associated with where elk might be killed if visited. Disadvantages in using kill sites is that they often are biased towards large prey that are more readily detected (Webb et al., 2008; Bacon et al., 2011), and adequate samples take considerable time to accumulate.

An alternative to kill sites is to combine spatial distributions of predators and contents of their scats. Scat contents reflective a predation event and the scat location indicates the broad-scale spatial overlap of predators and prey. A scat-based approach may be advantageous over telemetry-based kill sites because scats can be less invasive and more cost efficient when using scat-detection dogs (Wasser et al., 2004; Mumma et al., 2017), particularly in multi-predator communities. In this paper, we compare a scat-based approach to quantifying spatial predation risk from bears (Ursus arctos/U. americanus), cougars (Puma concolor ), coyotes ( $C$. latrans ), and wolves for a partially migratory elk population in the eastern slopes of the Rocky Mountains, Canada. We compared predictions of predator-scat occurrence combined with the relative probability of elk being in the scat to a model of predation risk from elk kill sites. We used this approach to assess expected differences in predation risk between migratory and resident elk on their summer ranges.

\section{Materials and methods:}

\section{STUDY AREA}

The study area encompassed the winter and summer ranges of the partially migratory Ya Ha Tinda elk herd along the eastern slopes of the Rocky Mountains in and adjacent to Banff National Park (BNP, Fig. 1). High-elevation bare rock and mixed shrub and herbaceous alpine communities dominated areas $>2,100 \mathrm{~m}$ in the west. Engelmann spruce (Picea engelmannii) and subalpine fir (Abies lasiocarpa) were the primary high-elevation conifer landcover, with low-elevation forests consisting of lodgepole pine (Pinus contorta) and white spruce (P. glauca). Early seral stands $(<20$-year stand age) consisted of logged areas (hereafter, "cutblocks") and post-fire forest regeneration.

Other ungulates in the area include white-tailed deer (Odocoileus virginianus), mule deer (O. hemionus ), moose, bighorn sheep (Ovis canadensis), mountain goats (Oreamnos americanus), and feral horses (Equus caballus ). Wolves naturally recolonized the study in the mid-1980s and continue to be relatively stable (Berg, 2019). Grizzly bears have increased in Alberta (Morehouse \& Boyce, 2016), and densities on protected federal land were 2.4 times higher than on provincial lands (Boulanger et al., 2005; Whittington \& Sawaya, 2015). Cougars expanded their range in northern and eastern Alberta since the 1990s (Knopff et al., 2014).

\section{SCAT COLLECTION AND ANALYSIS}

We used scat-detection dogs to detect predator scats during 1 July - 30 September, 2013 - 2016, along stratified random transects located in proportion to elevation classes and landcover representation within a systematic sampling grid of 575 x 5-km cells (see Spilker, 2019). We recorded scat diameter and physical description to identify scats to species (Weaver \& Fritts, 1979; Rezendes, 1992; Elbroch, 2003), and collected 
DNA on a subsample of scats to assess our accuracy. We combined grizzly and black bears into one ursid category because we found low accuracy in our ability to discriminate the two (Spilker, 2019).

We analyzed scat contents for the presence of elk hair using either macroscopic analysis or DNA analysis. For macroscopic analysis, we randomly selected 20 hairs from each scat, prepared hairs using standard methods (Ciucci et al., 1996), and identified the species based on characteristics of the hairs' medulla, cuticle scale patterns, and scale margin distance using dichotomous keys (Moore et al., 1974; Kennedy \& Carbyn, 1981). Three trained observers were subject to blind trials on known hairs, obtaining a minimum of $80 \%$ correct classification rate prior to analysis.

DNA was extracted from hair shafts using QIAGEN's DNeasy Tissue kits (QIAGEN Inc., Valencia, USA). Polymerase chain reaction (PCR) was used to amplify DNA and prey species identification was confirmed via a partial sequence analysis of a hypervariable region of the mitochondrial $16 \mathrm{~S}$ rRNA gene. This approach identified the most dominant prey species in the scat (i.e., based on the proportion of DNA); mixed samples where there was no dominant species (or equal amounts of DNA from each species) were re-run with ungulatespecific primers to determine if elk DNA was present. We compared the presence of elk from the DNA analysis to the macroscopic analysis on the same scats $(n=60)$ based on Area Under the Curve from a Receiver Operating Characteristic curve. We found DNA analysis detected elk present in $88 \%$ of the scats where we detected elk macroscopically. Wildlife Genetics International (Nelson, Canada) performed DNA analyses.

\section{SPATIAL PREDATION RISK}

Spatial predation risk $\left(\mathrm{PR}_{i j}\right)$ reflected the relative risk of an elk dying from a specific predator, $i$, at a location $j$, and was derived as:

$\mathrm{PR}_{i j}=\mathrm{RSF}_{i j} * \mathrm{P}_{i j}$ eqn 2

where $\mathrm{RSF}_{i j}$ is scat-based resource selection function, and $\mathrm{P}_{i j}$ is relative probability of elk being in the predator scat at the location. To estimate total risk from all predators (bear, cougar, coyote, or wolf), we summed the individual predation risk predictions standardized from $(0-1)$.

Relative probability of predator-scat occurrence

We developed RSFs for predators (Manly et al., 2002), where 'used' samples were the locations of predatorspecific scats along transect lines and 'available' samples were random locations within a 50-m buffer on each side of the line in a ratio of 1 scat:10 random points. We used an exponential RSF design fitted using logistic regression. We did not enter correlated variables $(r>|0.6|)$ into the same model. We used model selection and Akaike's Information Criterion corrected for small sample sizes $\left(\mathrm{AIC}_{\mathrm{c}}\right)$ to identify the best-supported RSF for each species using a criterion of four [?]AIC points to distinguish between competing models.

We used terrain, landcover, and anthropogenic features expected to influence predator occurrence (Nielsen et al., 2002; Whittington et al., 2005; Knopff et al., 2014).We measured landcover as cover type derived from TM Landsat Imagery, vegetation "greenness" from the Normalized Difference Vegetation Index (NDVI), forest fires [?] 14 years old (Hebblewhite, 2006), and cutblocks [?] 20 years since harvest (Visscher \& Merrill, 2009 ) as mean proportion of $30 \times 30-\mathrm{m}$ pixels within a $1.3-\mathrm{km}$ radius $\left(5.3-\mathrm{km}^{2}\right)$ buffer around a scat or random location. This buffer size reflected the average daily movement of black bears the shortest distance of all the predator species (see Appendix S1, Supporting Information). Forest edge was based on a 30-m buffer of conifer or mixed-deciduous forest with any other landcover type. We derived terrain features (slope, elevation, and terrain ruggedness) from a 30-m Digital Elevation Model. Locations were designated as within 30-m or farther than 30-m of a trail. Forest edge, proximity to roads, off-highway vehicle (motorized) trails, and waterways were measured as the shortest distance $(\mathrm{km})$ to the nearest feature or as density $\left(\mathrm{km} \mathrm{km}^{-2}\right)$ within the buffer. We compared the predictions of scat-based RSF of wolves and bears to a telemetry-based RSF at 1,000 random points. Scat-based RSF values increased as telemetry-based values increased, but was not strictly linear (Appendix S2, Supporting Information).

To include a numeric component, we weighted the wolf RSF by a probability density function (PDF) based 
on kill rates derived from annual, wolf pack size of collared packs (Hebblewhite \& Merrill, 2007; Berg, 2019), and weighted the RSF by the annual PDF in proportion of scats collected in each year. We weighted the grizzly bear RSF by estimates of grizzly bear densities, which were 2.4 times higher within BNP compared to outside of BNP ( Whittington \& Sawaya, 2015; Government of Alberta, 2016). We smoothed the PDF values along the BNP border using a 12.9-km moving window, the size corresponding to the average home range for local grizzly bears (Nielsen et al., 2002). RSFs of cougars and coyotes were not numerically weighted because no numeric indices were available.

\section{Relative probability of elk occurrence in predator scats}

To predict the relative probability of elk occurrence in a predator-specific scat $\left(\mathrm{P}_{i j}\right)$, we contrasted locations of scats containing elk ( $n=157: 24$ bear, 75 wolf, 42 coyote, and 16 cougar) to locations of a larger set of scats ( $n=870: 257$ bear, 363 wolf, 223 coyote, and 27 cougar) from the same predator species collected but not analysed for prey contents (Spilker, 2019), similar to a use/available design (Manly et al., 2002). By using scat locations as our available locations (rather than random locations), we controlled for the influence of landscape features on where predator scats were located. We avoided a presence-absence of elk in the scat design because the methods we used to detect elk in scats could not reliably confirm absence of elk. We used a model selection approach based on a $\Delta \mathrm{AIC}_{\mathrm{c}}>4$ to determine the model with the most support. We determined model covariates as the density or proportion within a buffer around a scat whose radius was derived from the mean gut passage time and movement per day (i.e., $3-\mathrm{km}$ for wolf, $1.5-\mathrm{km}$ for bear, and 2-km for cougar and coyote, Appendix S1, Supporting Information).

Covariates included green herbaceous biomass $\left(\mathrm{g} \mathrm{m}^{-2}\right)$ at the peak of the growing season (1 August), derived from a general linear model based on field sampling of 983 sites across the summer extent of the Ya Ha Tinda elk herd (Hebblewhite et al., 2008), and updated for changes in forage availability caused by climate, timber harvest, and fires (Smolko, 2014; MacAulay, 2019). Because elk must use the area to be found in the scat and encounters with elk are likely related to their intensity of use of an area, we also quantified relative intensity of elk use using a population-level resource utilization function (RUF; Marzluff et al., 2004) based on utilization distributions from 6-hour GPS relocations of 66 adult female elk during 2013 - 2016. Variables in the RUF included herbaceous forage biomass, herbaceous land cover (Hebblewhite et al., 2008), distance to nearest forest edge, burned vegetation ( $<15$ years), and wolf (Hebblewhite \& Merrill, 2007) and grizzly bear predation risk (Nielsen et al., 2002). For more detail, see MacAulay (2019).

\section{Scat-based vs. Kill-site Predation Risk}

We compared the predictions of total predation risk from all predators (i.e., sum of standardized predictions for each predator) based on scat locations and contents to predation risk to predictions derived at kill sites analysis at the known kill sites of collared and uncollared elk killed by predators between 2002 and 2016 (Appendix S3, Supporting Information). We derived kill-site models by comparing features at 104 locations of elk kill sites (1) to 20 random points (0) each using conditional logistic regression. Random points were generated within $13.2 \mathrm{~km}$ of each kill site, to account for the largest average movement per day of the predators (i.e. , cougar; Dickson et al., 2005; Laundré, 2005). Landscape variables were the percentage or mean value within a $250-\mathrm{m}$ buffer around the kill sites or random location. We used inverse frequency weighting to account for differences in number of kills by each predator species. We evaluated models with $\mathrm{AIC}_{\mathrm{c}}$ (Appendix S4, Supporting Information) and used the best-supported model to map predation risk to elk (Appendix S5, Supporting Information), assuming that the sample of elk mortalities reflected the relative predator-specific kill rates. We conducted Spearman rank correlations between predictions from scat-based and kill-site models at 1,000 random points, but graphically presented smoothed graphs based on the mean risk value of 10 equal-area bins.

\section{Results}

\section{SCAT-BASED PREDATOR RESOURCE SELECTION FUNCTIONS}

We surveyed $183 \mathrm{~km}$ in 2013, $652 \mathrm{~km}$ in 2014, and $405 \mathrm{~km}$ in 2015 for scats recording all predators, and an 
additional $82 \mathrm{~km}$ in 2016 for cougar scats only, for a total of 1,322 km over 125 transects. We used detections of 373 bear, 42 cougar, 223 coyote, and 470 wolf scats to determine RSFs. In all species, top RSFs were better supported than both the respective null and full candidate models with all 13 variables (Appendix S6, Supporting Information). Bears selected against conifer forests $(\beta=-0.71$, [95\% C.I. $-1.23,-0.19])$, motorized trails $(\beta=0.86$, [95\% C.I. 0.41, 1.31]), and roads $(\beta=0.00005$, [95\% C.I. $0.00003,0.00007])$, and for areas with cutblocks $(\beta=0.84$, [95\% C.I. $0.23,1.45])$, high NDVI $(\beta=0.0002$, [95\% C.I. 0.00007, 0.00033]), steep slopes $(\beta=0.02$, [95\% C.I. 0.019, 0.039]), and non-motorized trails, particularly when farther from areas with motorized trails $(\beta=0.00005$, [95\% C.I. 0.00001, 0.00009]; Table 1). Wolf scats most likely occurred near waterways $(\beta=-0.0001$, [95\% C.I. $-0.00015,-0.00005])$, on gentler slopes $(\beta=-0.04$, [95\% C.I. -0.06, -0.02]) and non-motorized trails $(\beta=1.29$, $[95 \%$ C.I0.99, 1.59]), but farther from motorized trails $(\beta=0.00005$, [95\% C.I. 0.00004, -0.00006]; Table 1).

Equally supported models for coyotes included areas with gentler slopes $(\beta=-0.05$, [95\% C.I. -0.08, -0.02]) and vehicle-restricted trails $(\beta=1.62$, [95\% C.I. 1.27, 1.97]), and areas farther from vehicle-permitted trails $(\beta=0.00006$, [95\% C.I. $0.00004,0.00008]$; Table 1$)$; we retained proportion of shrub cover $(\beta=2.63$, $[95 \%$ C.I. $0.21,5.05])$ because its confidence limits did not overlap zero. Cougar scats were more likely in areas with less conifer forest cover $(\beta=-1.92$, [95\% C.I. $-3.38,-0.46])$ and high edge density $(\beta=8.39$, [95\% C.I. $1.12,15.56])$ because the confidence limits of only these two variables did not overlap zero.

Based on model predictions, both wolf and bear scats were more likely found in the western portion of the study area along river drainages than in the eastern portion of the study area. Around the Ya Ha Tinda elk winter range, likelihood of scats was high for wolves but low for bears (Figs 2a, 2d). Cougar scats increased from the west (low) to east (high), corresponding with more forest edge in the forest-managed lands. Probability of coyote scat occurrence was fairly consistent across the study area (Figs 2b, c).

\section{ELK PRESENCE IN PREDATOR SCATS}

We analyzed the contents of 476 scats (130 bear, 33 cougar, 114 coyote, and 199 wolf); 226 were analyzed via macroscopic analysis and the remainder via DNA analysis. Elk was equally found in coyote (36\% of scats), wolf (38\%), and cougar (46\%) scats collected from across the study area (Wilcoxon Rank Sum test; all pairwise $P$ [?] 0.27). Bear scats contained elk less frequently compared to the three other predators (19\%, all pairwise $P<0.001)$. We did not use herbaceous forage biomass and elk resource use (RUF) in the same models for predicting elk in a scat, nor did we use slope, elevation, and ruggedness in the same models because they were highly correlated $(r>0.60)$

The best-supported, predator-specific models predicting elk presence in a scat included most consistently the positive effect of herbaceous biomass, except for cougar; inclusion of other variables depended on the predator species (Table 2). For bears, the top model included the positive effect of herbaceous biomass $(\beta$ $=0.061$, [95\% C.I. 0.03, 0.10]), and negative effect of open cover type $(\beta=-4.83$, [95\% C.I. -8.58, -1.63], Table 2). For wolves, we selected the model including only herbaceous biomass $(\beta=0.21$, [95\% C.I. 0.16, $0.27])$, terrain ruggedness $(\beta=0.84$, $[95 \%$ C.I. $0.53,1.19])$, and percent of area covered by deciduous forest $(\beta=-36.29$, [95\% C.I. $-56.85,-18.25]$; Table 2$)$ because the confidence limits of the beta coefficient for burns included zero (Appendix S7, Supporting Information). We selected the model for elk presence in coyote scat that included the positive effects of herbaceous biomass $(\beta=0.048$, $[95 \%$ C.I. 0.030, 0.070]) and distance to water $(\beta=0.00032$, [95\% C.I. 0.000060, 0.00058]) and the negative effect of road density $(\beta=-0.88,[95 \%$ C.I. -1.83, -0.13]; Table 2). The most uncertainty was found in the models of elk presence in cougar scats largely because of low sample size (Appendix S7, Supporting Information). Based on parsimony, we selected the model with only forest edge density ( $\beta=1.25$, [95\% C.I. 0.31, 2.49]; Table 2$)$.

The western portion of the study area (i.e., BNP) had low relative probability of elk being in all predator scats. Predictions from the above models indicated elk were most likely found in cougar scats in the eastern part of the study area and wolf and coyote scats at Ya Ha Tinda (Figs 2-3, Table 3).

\section{SCAT-BASED PREDATION RISK TO ELK}


In combining predator distribution and scat contents, the predation risk to elk was highest from wolves and coyotes at the Ya Ha Tinda (Table 3) where resident elk summer. Risk from bears was highest for areas west of Ya Ha Tinda and at the Ya Ha Tinda. In contrast, risk from cougars was widespread and relatively high only east of the Ya Ha Tinda (Table 3). Highest total predation risk to elk from all predators occurred for the YHT resident elk (Table 3). Rank correlation of the total risk (all predators combined; Fig. 4) corresponded well with predation risk inferred from kill sites $\left(r_{s}=0.98, P<0.0001\right.$; Appendix S8, Supporting Information).

\section{Discussion}

Because different factors may influence where prey are encountered and killed (Hebblewhite, Merrill, \& McDonald, 2005; Kauffman et al., 2007), predictions of spatial risk based only on predator distribution may not be sufficient to assess predation risk in terms of an actual mortality event but this distinction is rarely acknowledged (Moll et al., 2017). At the same time, knowing the likelihood of predators being present may be sufficient to address questions regarding prey responses and frequency of anti-predator behaviours (Robinson \& Merrill, 2013).Indeed, Prugh et al., (2019) argued for even further expansion of the stages of predation to include engaging, attacking, and surviving given an encounter to adequately understand and address questions of predation risk. However, quantifying these stages is challenging and likely requires time-intensive, observational studies (Wikenros et al., 2009; Tallian et al., 2017), or detailed fine-scale movements of both predators and prey (Basille et al., 2015; Greggor et al., 2016). Where risk of mortality is desired, the most common approach has been to examine kill-sites. Kill-site data based on annual winter mortality surveys or marked animals require extended periods and expense to accumulate sufficient samples, giving an approach based on scats a distinct advantage in assessing predation risk early in a study. It is also advantageous in terms of being non-invasive and cost-efficient (Wasser et al., 2004; Orkin et al., 2016), particularly a multi-predator community because dogs can simultaneously find scats from multiple predators. At the same time, reliability of using fecal material to estimate predator distribution has been questioned because of false species identification and sampling biases (Morin et al., 2016; DeMatteo et al., 2018). We found distinguishing between scats of bear species was more difficult than anticipated and warrants DNA analysis to verify species where the uncertainty needs to be eliminated. Biases in detecting scats, can be addressed with refined training and handling of dogs. For example, in the blind trials we performed, dogs had a high $(>90 \%)$ detection rate of scats (Spilker, 2019). Potential biases in sampling designs, such as collecting scats only on trails can be problematic (Steenweg et al., 2015), but we remedied this by locating transects on and off trails. Nevertheless, features such as steep cliffs and rugged terrain can constrain sampling, whereas this may not be the case if large carcasses can be observed during aerial flights.

A second issue for using scats for sampling the distribution of any species relates to whether deposition reflects where they spend time, and in the case of predators, where they make an actual kill. We present evidence for scat location and contents corresponding to these two components of predation because the factors we found associated with scat locations and contents (i.e. elk) were similar to those reported by others for both the distribution of these predators and for elk kill sites. For example bear scats were associated with high forage quality (NDVI) and quantity (cutblocks), similar to models for grizzly bears where bears were associated with greenness and open canopy cover (Nielsen et al., 2002; Apps et al., 2004). Wolf scats were associated with flat areas (Hebblewhite \& Merrill, 2007) and cougar scats were associated with areas of high forest edge (Atwood et al., 2009; Elbroch et al., 2013). Indeed, we found that for wide-ranging species like wolves and grizzly bears, predictions from the scat-based RSFs corresponded well with predictions from telemetry-based RSFs in the study area (Appendix S2, Supporting Information). The ability of our scat-based approach to make predictions similar to the kill-site analysis also is not surprising because the approaches include the same components of predation, i.e. , a risky place is one where there is a high probability of encountering and being killed by a predator. For example, elk select for areas with abundant forage biomass in summer (Hebblewhite \& Merrill, 2009; Smolko 2014), which is where we found a higher probability of elk being present in the scat of all species; we also found elk being in wolf scats associated with rugged terrain, which is where Torretta et al., (2018) also reported wolf kill sites, suggesting ruggedness reduced agility to navigate in steep terrain. 
A major consideration in developing and applying estimates of spatial risk is to appropriately match the approach to the spatial and temporal scales for the processes and questions addressed (Moll et al., 2017; Cusack et al., 2019; Prugh et al., 2019). For example, experimental approaches such as giving-up densities (Altendorf et al., 2001) or interactions caught on remote cameras (Hernández et al., 2005) may be most appropriate to make fine-scale, behavioral or site-specific inferences of predation risk, whereas simultaneously monitoring sequential movements of predators and prey at short temporal scales may lead to understanding how certain evasion tactics are successful in only limited situations. Here, we show that a scat-based approach to predicting predation risk for elk corresponds well with outputs derived from modeling kill sites, but submit the approach is most appropriate when directed at answering questions at broad spatial and temporal scales (Orkin et al., 2016). For example, because it was not feasible to collect sufficient scats except over a 12-week summer season, we gained little insight into the seasonal dynamics of predation risk. At the same time, the broad-scale spatial patterns in predation risk for elk we found are consistent with our demographic understanding of predation rates on both adult and calf elk in this area ( Hebblewhite et al., 2018; Berg, 2019). Strengthening the link between risk of predation from the perspective of the prey, as represented in the above metrics, and kill or predation rates is a key next step for addressing questions of predator-prey dynamics.

ConclusionWe illustrate a new approach for estimating predation risk to prey based on distribution and contents of predator scats using scat dogs, and found it corresponds well with the results of other approaches. It has the advantage of being able to distinguish key components of predation, such as where prey may encounter predators and where they are killed. It can be used to sample broad areas over a relatively short time frame to get a snapshot of spatial predation risk, which lends itself to repeat sampling for detecting changes in spatial risk in the same area over time. As with other methods, appropriate sampling design and reducing uncertainty with observer training (e.g., dogs and handlers) and auxiliary data such as DNA to confirm species identification will be key considerations.

\section{Acknowledgements}

We thank G. Stenhouse of Foothills Research Institute for contributing data on grizzly bear resource selection functions. M. O'Donnell, N. Klappstein, R. Baldini, J. Melsted, D. Nichols, and D. Paches assisted in scat and laboratory analyses. Financial and in-kind support was provided by Alberta Conservation Association, Alberta Environment and Parks, Colleges and Institutes Canada - CleanTech Internship, International Association for Bear Research and Management, National Science Foundation Long-term Research in Environmental Biology grant to MH and EHM (1556248), Natural Sciences and Engineering Research Council Discovery Grant to EHM, Parks Canada, Rocky Mountain Elk Foundation, Safari Club International Northern Alberta Chapter, Sundre Forest Products, TD Bank - Friends of the Environment Foundation, University of Alberta, University of Montana, and the Wild Sheep Foundation of Alberta. All field data collection were in accordance with the Canadian Council on Animal Care Guidelines and approved by the University of Alberta Animal Care and Use Committee (AUP00000624).

\section{Authors' contributions.}

KMM, EGS, EHM conceived the ideas and designed methodology; KMM, EGS, JEB collected the data; KMM, EGS analysed the data; KMM, EHM led the writing of the manuscript. All authors contributed critically to the drafts and gave final approval for publication.

\section{Data Availability}

Data are intended to be archived on the Dryad Digital Repository

\section{References}

Altendorf, K. B., Laundré, J. W., Lopez Gonzalez, C. A., \& Brown, J. S. (2001). Assessing effects of predation risk on foraging behavior of mule deer. Journal of Mammalogy , 82 (2), 430-439. doi:https://doi.org/10.1644/1545-1542(2001)082<0430:AEOPRO>2.0.CO;2 
Apps, C. D., McLellan, B. N., Woods, J. G., \& Proctor, M. F. (2004). Estimating grizzly bear distribution and abundance relative to habitat and human influence. Journal of Wildlife Management ,68 (1), 138-152. doi:10.2193/0022-541x(2004)068[0138:egbdaa]2.0.co;2

Atwood, T. C., Gese, E. M., \& Kunkel, K. E. (2009). Spatial partitioning of predation risk in a multiple predator-multiple prey sytem. Journal of Wildlife Management, 73 (6), 876-884. doi:10.2193/2008-325

Bacon, M. M., Becic, G. M., Epp, M. T., \& Boyce, M. S. (2011). Do GPS clusters really work? Carnivore diet from scat analysis and GPS telemetry methods. Wildlife Society Bulletin , 35 (4), 409-415. doi:10.1002/wsb.85

Basille, M., Fortin, D., Dussault, C., Bastille-Rousseau, G., Ouellet, J.-P., \& Courtois, R. (2015). Plastic response of fearful prey to the spatiotemporal dynamics of predator distribution. Ecology ,96 (10), 2622-2631. doi:10.1890/14-1706.1

Berg, J. E. (2019). Shifts in strategy: Calving and calf survival in a partially migratory elk population. Doctoral Dissertation.University of Alberta. doi:/https://doi.org/10.7939/r3-y2h3-b976

Boulanger, J., Stenhouse, G., MacHutchon, G., Proctor, M., Himmer, S., Paetkau, D., \& Cranston, J. (2005). Grizzly bear population density estimates for the 2005 Alberta (proposed) Unit 4 Management Area inventory. Report Prepared for Alberta Sustainable Resource Development, Fish and Wildlife Division, (December), $31 \mathrm{pp}$.

Christianson, D., \& Creel, S. (2010). A nutritionally mediated risk effect of wolves on elk. Ecology , 91 (4), 1184-1191. doi:10.1890/09-0221.1

Ciucci, P., Boitani, L., Pelliccioni, E. R., Rocco, M., \& Guy, I. (1996). A comparison of scatanalysis methods to assess the diet of the wolf Canis lupus. Wildlife Biology , 2 (1), 37-48. doi:https://doi.org/10.2981/wlb.1996.006

Creel, S., Winnie Jr, J., Maxwell, B., Hamlin, K., \& Creel, M. (2005). Elk alter habitat selection as an antipredator response to wolves.Ecology , 86 (12), 3387-3397. doi:https://doi.org/10.1890/05-0032

Cusack, J. J., Kohl, M. T., Metz, M. C., Coulson, T., Stahler, D. R., Smith, D. W., \& Macnulty, D. R. (2019). Weak spatiotemporal response of prey to predation risk in a freely interacting system. Journal of Animal Ecology , 89 , 120-131. doi:10.1111/1365-2656.12968

DeMatteo, K. E., Blake, L. W., Young, J. K., \& Davenport, B. (2018). How behavior of nontarget species affects perceived accuracy of scat detection dog surveys. Scientific Reports , 8 , 13830. doi:10.1038/s41598018-32244-1

Dickson, B. G., Jenness, J. S., \& Beier, P. (2005). Influence of vegetation, topography, and roads on cougar movement in southern California. Journal of Wildlife Management , 69 (1), 264-276. doi:10.2193/0022$541 \mathrm{X}(2005) 069<0264:$ IOVTAR $>2.0 . \mathrm{CO} ; 2$

Elbroch, L. M., Lendrum, P. E., Newby, J., Quigley, H., \& Craighead, D. (2013). Seasonal foraging ecology of non-migratory cougars in a system with migrating prey. PLoS ONE , 8 (12), 1-14. doi:10.1371/journal.pone.0083375

Elbroch, M. (2003). Mammal tracks and sign - A guide to North American species . Mechanicsburg, Pennsylvania: Stackpole Books.

Eriksen, A., Wabakken, P., Zimmermann, B., Andreassen, H. P., Arnemo, J. M., Gundersen, H., ... Storaas, T. (2009). Encounter frequencies between GPS-collared wolves (Canis lupus) and moose (Alces alces) in a Scandinavian wolf territory. Ecological Research ,24 (3), 547-557. doi:10.1007/s11284-008-0525-x

Government of Alberta. (2016). Alberta Grizzly Bear ( Ursus arctos) Recovery Plan 2016-2021 . Edmonton, Alberta, Canada: Alberta Environment and Parks, Wildlife Management Branch. 
Greggor, A. L., Berger-Tal, O., Blumstein, D. T., Angeloni, L., Bessa-Gomes, C., Blackwell, B. F., ... Sutherland, W. J. (2016). Research priorities from animal behaviour for maximising conservation progress. Trends in Ecology $\&$ Evolution, 31 (12), 953-964. doi:10.1016/j.tree.2016.09.001

Gustine, D. D., Parker, K. L., Lay, R. J., Gillingham, M. P., \& Heard, D. C. (2006). Calf survival of woodland caribou in a multi-predator ecosystem. Wildlife Monographs , (165), 1-32. doi:10.2193/0084-0173(2006)165

Hebblewhite, M. (2006). Linking predation risk and forage to ungulate population dynamics. Doctoral Dissertation. University of Alberta, Edmonton, Alberta, Canada.

Hebblewhite, M, Eacker, D. R., Eggeman, S., Bohm, H., \& Merrill, E. H. (2018). Density-independent predation affects migrants and residents equally in a declining partially migratory elk population. Oikos ,127 , 1304-1318. doi:10.1111/oik.05304

Hebblewhite, M., \& Merrill, E. H. (2009). Trade-offs between wolf predation risk and forage at multiple spatial scales in a partially migratory ungulate. Ecology , 90 (12), 3445-3454. doi:https://doi.org/10.1890/08-2090.1

Hebblewhite, M., Merrill, E. H., \& McDermid, G. (2008). A multi-scale test of the forage maturation hypothesis in a partially migratory ungulate population. Ecological Monographs , 78 (2), 141-166. doi:https://doi.org/10.1890/06-1708.1

Hebblewhite, M., Merrill, E. H., \& McDonald, T. L. (2005). Spatial decomposition of predation risk using resource selection functions: an example in a wolf-elk predator-prey system. Oikos , 111 (1), 101-111. doi:https://doi.org/10.1111/j.0030-1299.2005.13858.x

Hebblewhite, M., \& Merrill, E. H. (2007). Multiscale wolf predation risk for elk: Does migration reduce risk? Oecologia ,152 (2), 377-387. doi:10.1007/s00442-007-0661-y

Hebblewhite, M., Merrill, E. H., Morgantini, L. E., White, C. A., Allen, J. R., Bruns, E., .. Hurd, T. E. (2006). Is the migratory behavior of montane elk herds in peril? The case of Alberta's Ya Ha Tinda elk herd. Wildlife Society Bulletin , 34 (5), 1280-1294. doi:10.2193/0091-7648(2006)34[1280:ITMBOM]2.0.CO;2

Hernández, L., Laundré, J. W., \& Gurung, M. (2005). Use of camera traps to measure predation risk in a puma-mule deer system. Wildlife Society Bulletin , 33 (1), 353-358. doi:10.2193/00917648(2005)33[353:ftfuoc]2.0.co;2

Holling, C. S. (1959). The components of predation as revealed by a study of small mammal predation on the European pine sawfly.Canadian Entomology , 91 , 293-320. doi:https://doi.org/10.4039/Ent91293-5

Kauffman, M. J., Varley, N., Smith, D. W., Stahler, D. R., MacNulty, D. R., \& Boyce, M. S. (2007). Landscape heterogeneity shapes predation in a newly restored predator-prey system. Ecology Letters ,10 (8), 690-700. doi:10.1111/j.1461-0248.2007.01059.x

Kennedy, A. J., \& Carbyn, L. N. (1981). Identification of wolf prey using hair and feather remains . Edmonton, Alberta, Canada: Canadian Wildlife Service.

Knopff, A. A., Knopff, K. H., Boyce, M. S., \& St. Clair, C. C. (2014). Flexible habitat selection by cougars in response to anthropogenic development. Biological Conservation , 178, 136-145. doi:10.1016/j.biocon.2014.07.017

Knopff, K. H., Webb, N. F., \& Boyce, M. S. (2014). Cougar population status and range expansion in Alberta during 1991-2010. Wildlife Society Bulletin , 38 (1), 116-121. doi:10.1002/wsb.369

Laundré, J. W. (2005). Puma energetics: A recalculation. Journal of Wildlife Management, 69 (2), 723-732. doi:https://doi.org/10.2193/0022-541X(2005)069[0723:PEAR]2.0.CO;2

Lima, S. L., \& Dill, L. M. (1990). Behavioral decisions made under the risk of predation: a review and prospectus. Canadian Journal of Zoology , 68 (4), 619-640. doi:10.1139/z90-092 
MacAulay, K. M. (2019). Spatial predation risk for elk in a multi-predator community on the Rocky Mountains East Slopes, Alberta. Masters Thesis . University of Alberta. doi:/https://doi.org/10.7939/r3-e4wq-bh87

Manly, B. F. J., McDonald, L. L., Thomas, D. L., McDonald, T. L., \& Erickson, W. P. (2002). Resource selection by animals: Statistical design and analysis for field studies. Statistical Design and Analysis for Field Studies Second Edition . doi:10.1017/S0376892904241224

Marzluff, J. M., Millspaugh, J. J., Hurvitz, P., \& Handcock, M. S. (2004). Relating resources to a probabilistic measure of space use: Forest fragments and Steller's Jays. Ecology , 85 (5), 1411-1427. doi:https://doi.org/10.1890/03-0114

Moll, R. J., Redilla, K. M., Mudumba, T., Muneza, A. B., Gray, S. M., Abade, L., ... Montgomery, R. A. (2017). The many faces of fear: a synthesis of the methodological variation in characterizing predation risk. Journal of Animal Ecology , 86 (4), 749-765. doi:10.1111/1365-2656.12680

Moore, T. D., Spence, L. E., \& Dugnolle, C. E. (1974).Identification of the dorsal guard hairs of some mammals of Wyoming. Cheyenne, Wyoming, USA: Wyoming Game and Fish Department.

Morehouse, A. T., \& Boyce, M. S. (2016). Grizzly bears without borders: Spatially explicit capture-recapture in southwestern Alberta.Journal of Wildlife Management , 80 (7), 1152-1166. doi:10.1002/jwmg.21104

Morin, D. J., Higdon, S. D., Holub, J. L., Montague, D. M., Fies, M. L., Waits, L. P., \& Kelly, M. J. (2016). Bias in carnivore diet analysis resulting from misclassification of predator scats based on field identification. Wildlife Society Bulletin , 40 (4), 669-677. doi:10.1002/wsb.723

Mumma, M. A., Holbrook, J. D., \& Rayl, N. D. (2017). Examining spatial patterns of selection and use for an altered predator guild.Oecologia , 185 , 725-735. doi:10.1007/s00442-017-3971-8

Nielsen, S. E., Boyce, M. S., Stenhouse, G. B., \& Munro, R. H. M. (2002). Modeling grizzly bear habitats in the Yellowhead Ecosystem of Alberta: Taking autocorrelation seriously. Ursus , 13 (13), 45-56.

Orkin, J. D., Yang, Y., Yang, C., Yu, D. W., \& Jiang, X. (2016). Cost-effective scat-detection dogs: unleashing a powerful new tool for international mammalian conservation biology. Scientific Reports ,6 (34758). doi:10.1038/srep34758

Prugh, L. R., Sivy, K. J., Mahoney, P. J., Ganz, T. R., Ditmer, M. A., Kerk, M. Van De, ... Montgomery, R. A. (2019). Designing studies of predation risk for improved inference in carnivore- ungulate systems.Biological Conservation ,232 , 194-207. doi:10.1016/j.biocon.2019.02.011

Rezendes, P. (1992). Tracking and the art of seeing, 2nd edition: How to read animal tracks and signs. New York City, New York: Harper Collins.

Robinson, B. G., \& Merrill, E. H. (2013). Foraging-vigilance trade-offs in a partially migratory population: Comparing migrants and residents on a sympatric range. Animal Behaviour , 85 (4), 849-856. doi:10.1016/j.anbehav.2013.02.004

Smith, D. W., Drummer, T. D., Murphy, K. M., Guernsey, D. S., \& Evans, S. B. (2005). Winter prey selection and estimation of wolf kill rates in Yellowstone National Park, 1995-2000. Journal of Wildlife Management , 68 (1), 153-166. doi:10.2193/0022-541x(2004)068[0153:wpsaeo]2.0.co;2

Smolko, P. (2014). Ekológia parciálne migrujúcich populácií jelena lesného(Cervus elaphus). Doctoral Dissertation. Technická Univerzita Vo Zvolene.

Spilker, E. (2019). Spatial predation risk and interactions within a predator community on the Rocky Mountain East Slopes, Alberta. Masters Thesis . University of Alberta. doi:/https://doi.org/10.7939/r3-ncbn-ad81

Steenweg, R., Gillingham, M. P., Parker, K. L., \& Heard, D. C. (2015). Considering sampling approaches when determining carnivore diets: The importance of where, how, and when scats are collected. Mammal Research , 60 , 207-216. doi:10.1007/s13364-015-0222-4 
Tallian, A., Smith, D. W., Stahler, D. R., Metz, M. C., Wallen, R. L., Geremia, C., .. Macnulty, D. R. (2017). Predator foraging response to a resurgent dangerous prey. Functional Ecology , 31 , 1418-1429. doi:10.1111/1365-2435.12866

Thaker, M., Vanak, A. T., Owen, C. R., Ogden, M. B., Niemann, S. M., \& Slotow, R. (2011). Minimizing predation risk in a landscape of multiple predators: effects on the spatial distribution of African ungulates.Ecology , 92 (2), 398-407. doi:https://doi.org/10.1890/10-0126.1

Theuerkauf, J., \& Rouys, S. (2008). Habitat selection by ungulates in relation to predation risk by wolves and humans in the Białowieża Forest, Poland. Forest Ecology and Management , 256 (6), 1325-1332. doi:10.1016/j.foreco.2008.06.030

Tolon, V., Dray, S., Loison, A., Zeileis, A., Fischer, C., \& Baubet, E. (2009). Responding to spatial and temporal variations in predation risk: space use of a game species in a changing landscape of fear. Canadian Journal of Zoology , 87 (12), 1129-1137. doi:10.1139/Z09-101

Torretta, E., Caviglia, L., Serafini, M., \& Meriggi, A. (2018). Wolf predation on wild ungulates: How slope and habitat cover influence the localization of kill sites. Current Zoology , 64 (3), 271-275. doi:10.1093/cz/zox031

Visscher, D. R., \& Merrill, E. H. (2009). Temporal dynamics of forage succession for elk at two scales: Implications of forest management.Forest Ecology and Management , 257 (1), 96-106. doi:10.1016/j.foreco.2008.08.018

Wasser, S. K., Davenport, B., Ramage, E. R., Hunt, K. E., Parker, M., Clarke, C., \& Stenhouse, G. (2004). Scat detection dogs in wildlife research and management: application to grizzly and black bears in the Yellowhead Ecosystem, Alberta, Canada. Canadian Journal of Zoology , 82 (3), 475-492. doi:10.1139/z04020

Weaver, J. L., \& Fritts, S. H. (1979). Comparison of coyote and wolf scat diameters. Journal of Wildlife Management , 43 (3), 786-788. doi:https://doi.org/10.2307/3808765

Webb, N. F., Hebblewhite, M., \& Merrill, E. H. (2008). Statistical methods for identifying wolf kill sites using global positioning system locations. Journal of Wildlife Management, 72 (3), 798-807. doi:10.2193/2006566

White, P. J., Garrott, R. A., Borkowski, J. J., Hamlin, K. L., \& Berardinelli, J. G. (2009). Elk nutrition after wolf recolonization of Central Yellowstone. In R. A. Garrott, P. J. White, \& F. G. R. Watson (Eds.), The Ecology of Large Mammals in Yellowstone: Sixteen Years of Integrated Field Studies (1st ed., pp. 477-488). San Diego, California: Academic Press. doi:10.1016/S1936-7961(08)00222-4

Whittington, J., Hebblewhite, M., Decesare, N. J., Neufeld, L., Bradley, M., Wilmshurst, J., \& Musiani, M. (2011). Caribou encounters with wolves increase near roads and trails: A time-to-event approach.Journal of Applied Ecology , 48 (6), 1535-1542. doi:10.1111/j.1365-2664.2011.02043.x

Whittington, J., \& Sawaya, M. A. (2015). A comparison of grizzly bear demographic parameters estimated from non-spatial and spatial open population capture-recapture models. PLoS ONE , 10 (7), 1-17. doi:10.1371/journal.pone.0134446

Whittington, J., St. Clair, C. C., \& Mercer, G. (2005). Spatial responses of wolves to roads and trails in mountain valleys.Ecological Applications , 15 (2), 543-553. doi:https://doi.org/10.7939/R3S756R71

Wikenros, C., Sand, H. D., Wabakken, P., Liberg, O., Pedersen, H. C., Wikenros, C., ... Wolf, P. H. C. (2009). Wolf predation on moose and roe deer: Chase distances and outcome of encounters. Acta Theriologica , 54 (3), 207-218. doi:10.4098/j.at.0001

Tables and Figures 


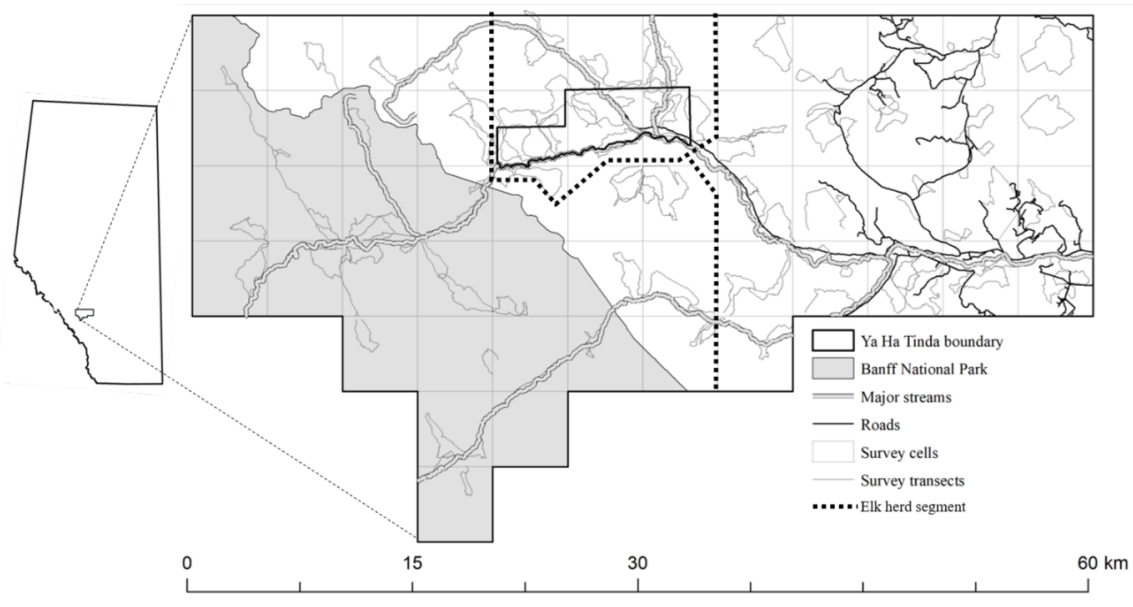



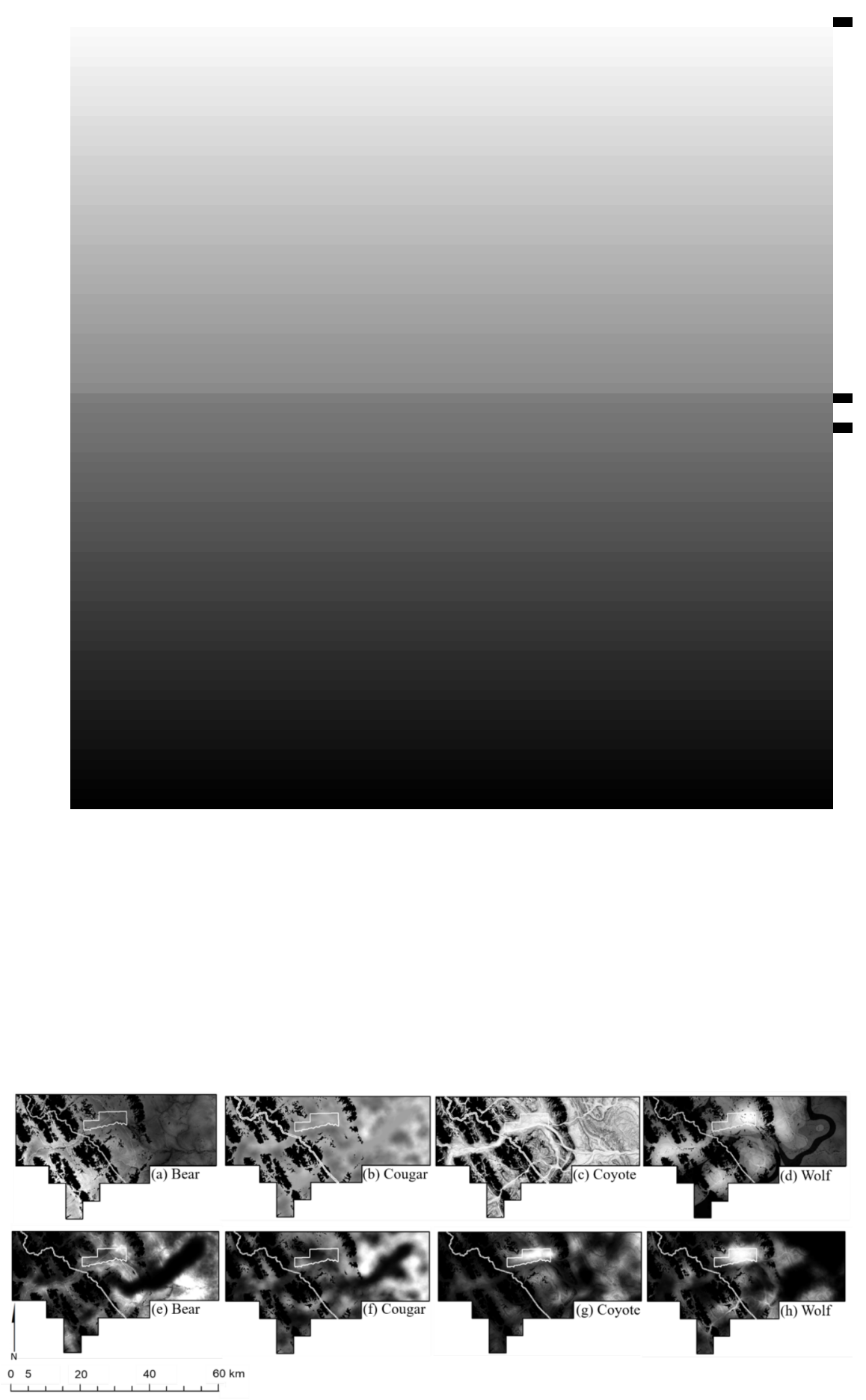

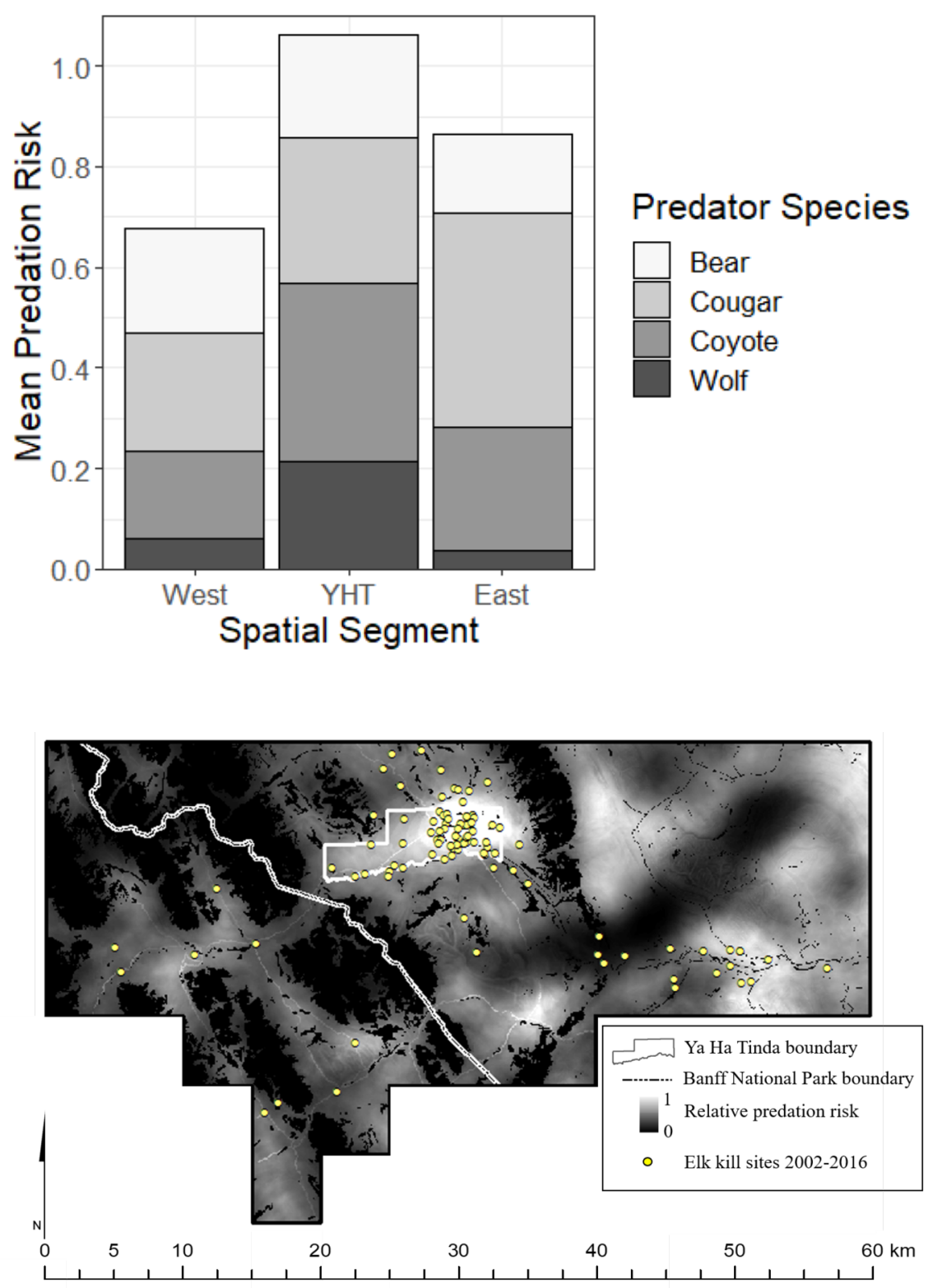

Table 1. Beta coefficients $(\beta)$ and upper and lower $95 \%$ confidence intervals (CI) for the top scat-based resource selection functions (RSF) for four carnivores in the eastern slopes of the Rocky Mountains, Alberta, Canada, 2013 - 2016.

\begin{tabular}{llllll}
\hline Species & Variable & $\beta$ & $95 \% C I$ & $95 \% C I$ & $95 \% C I$ \\
& & & Lower & Upper & \\
Bear & Conifer forest & -0.71 & -1.23 & -0.19 & \\
& Cutblocks & 0.84 & 0.23 & 1.45 & \\
& NDVI & 0.0002 & 0.00007 & 0.00033 \\
& Slope & 0.02 & 0.019 & 0.039 & \\
& Non-motorized trail use & 0.86 & 0.41 & 1.31
\end{tabular}




\begin{tabular}{|c|c|c|c|c|}
\hline & Distance to motorized trail/road & 0.00005 & 0.00003 & 0.00007 \\
\hline & Non-motorized trail use*Distance to motorized trail/road & 0.00005 & 0.00001 & 0.00009 \\
\hline \multirow[t]{2}{*}{ Cougar } & Conifer forest & -1.92 & -3.38 & -0.46 \\
\hline & Forest edge density & 8.39 & 1.12 & 15.56 \\
\hline \multirow[t]{4}{*}{ Coyote } & Shrub & 2.63 & 0.21 & 5.05 \\
\hline & Slope & -0.05 & -0.08 & -0.02 \\
\hline & Non-motorized trail use & 1.62 & 1.27 & 1.97 \\
\hline & Distance to motorized trail/road & 0.00006 & 0.00004 & 0.00008 \\
\hline \multirow[t]{5}{*}{ Wolf } & Distance to streams & -0.0001 & -0.00015 & -0.00005 \\
\hline & Cutblocks & -2.47 & -4.48 & -0.46 \\
\hline & Slope & -0.04 & -0.06 & -0.02 \\
\hline & Non-motorized trail use & 1.29 & 0.99 & 1.59 \\
\hline & Distance to motorized trail/road & 0.00005 & 0.00004 & 0.00006 \\
\hline
\end{tabular}

Table 2. Beta coefficients $(\beta)$ and lower and upper confidence intervals (CI) for the top predator-specific models predicting the relative probability of elk occurrence in scat based on Akaike's Information Criterion corrected for small sample sizes $\left(\mathrm{AIC}_{\mathrm{c}}\right)$ for four predators along the eastern slopes of the Rocky Mountains, Alberta, Canada, 2013 - 2016.

\begin{tabular}{lllll}
\hline Species & Variable & $\beta$ & $\begin{array}{l}95 \% \text { CI } \\
\text { Lower }\end{array}$ & $\begin{array}{l}95 \% \text { CI } \\
\text { Upper }\end{array}$ \\
Bear & Herbaceous forage biomass & 0.06 & 0.03 & 0.10 \\
& Open cover & -4.83 & -8.58 & -1.63 \\
Cougar & Forest edge density & 1.25 & 0.31 & 2.49 \\
Coyote & Herbaceous forage biomass & 0.050 & 0.030 & 0.070 \\
& Distance to streams & 0.00032 & 0.00006 & 0.00058 \\
& Motorized road/trail density & -0.88 & -1.83 & -0.13 \\
\multirow{2}{*}{ Wolf } & Herbaceous forage biomass & 0.21 & 0.16 & 0.27 \\
& Terrain ruggedness & 0.85 & 0.53 & 1.19 \\
& Deciduous-mixed forest & -36.29 & -56.85 & -18.25 \\
\hline
\end{tabular}

Table 3. Mean \pm standard deviation of predicted values across space for three models $(\mathrm{RSF}=$ scat-based resource selection functions; $P_{\text {elk }}=$ probability of elk presence in scat; Predation Risk $=$ eqn 2 ) for four predators along the eastern slopes of the Rocky Mountains, Alberta, Canada, 2013 - 2016.

\begin{tabular}{lllll}
\hline \multirow{6}{*}{ Bear } & Spatial Segment & Mean RSF & Mean $P_{\text {elk }}$ & Mean Predation Risk \\
& West & $0.438 \pm 0.134$ & $0.145 \pm 0.108$ & $0.207 \pm 0.139$ \\
& YHT & $0.243 \pm 0.062$ & $0.250 \pm 0.115$ & $0.204 \pm 0.09$ \\
Cougar & East & $0.186 \pm 0.049$ & $0.254 \pm 0.215$ & $0.156 \pm 0.132$ \\
& West & $0.585 \pm 0.118$ & $0.389 \pm 0.177$ & $0.237 \pm 0.116$ \\
& YHT & $0.577 \pm 0.082$ & $0.495 \pm 0.213$ & $0.288 \pm 0.127$ \\
& East & $0.635 \pm 0.113$ & $0.638 \pm 0.308$ & $0.426 \pm 0.247$ \\
\multirow{5}{*}{ Woyote } & West & $0.732 \pm 0.163$ & $0.210 \pm 0.112$ & $0.172 \pm 0.092$ \\
& YHT & $0.796 \pm 0.127$ & $0.405 \pm 0.218$ & $0.354 \pm 0.21$ \\
& East & $0.783 \pm 0.112$ & $0.291 \pm 0.174$ & $0.244 \pm 0.15$ \\
& West & $0.209 \pm 0.168$ & $0.296 \pm 0.171$ & $0.062 \pm 0.066$ \\
& YHT & $0.341 \pm 0.223$ & $0.479 \pm 0.291$ & $0.215 \pm 0.232$ \\
& East & $0.114 \pm 0.116$ & $0.222 \pm 0.257$ & $0.037 \pm 0.071$ \\
\hline
\end{tabular}

